Proc. Indian Acad. Sci. (Chem. Sci.), Vol. 98, No. 3, March 1987, pp. 207-212.

(C) Printed in India

\title{
Substituent effects on carbon-13 NMR chemical shifts of side chain carbonyl carbons of 4-substituted 1-naphthamides
}

\author{
K RAJASEKARAN, C GNANASEKARAN* and T C WONG $\dagger$ \\ Department of Chemistry, VHNSN College, Virudhunagar 626001 , India \\ Department of Chemistry, University of Missouri, Columbia, USA.
}

MS received 30 June 1986; revised 13 October 1986

\begin{abstract}
Substituent induced ${ }^{13} \mathrm{C}$ NMR chemical shifts of side chain carbonyl carbons of several 4-substituted 1-naphthamides have been measured in DMSO- $d_{6}$ solvent. Analysis of the substituent induced chemical shifts by the DSP equation gave the regression equation. Both $\rho_{I}$ and $\rho_{R}$ values were negative. The negative sign on $\rho_{I}$ term indicates the operation of a reverse substituent effect and that $\pi$-polarisation is the important mechanism for the transmission of substituent effects by inductive effect. The perihydrogen interaction in naphthamides forces the amide group out of the plane of the naphthalene ring.
\end{abstract}

Keywords. Naphthamides; substituent chemical shifts; reverse substituent effect; $\pi$-polarisation.

\section{Introduction}

In recent years much attention has been paid to correlate the substituent induced ${ }^{13} \mathrm{C}$ NMR chemical shifts of aromatic compounds with the Hammett substituent constants. The effect of substituents in the ring on the chemical shifts of side chain carbon is of obvious interest, especially in those cases where the side chain carbon is capable of conjugating with the ring. Correlation of ${ }^{13} \mathrm{C} N \mathrm{NMR}$ chemical shifts of $\pi$-bonded groups conjugated with substituted aryl rings have appeared for several classes of compounds such as styrenes (Dhami and Stothers 1965; Hamer et al 1973), phenylacetylenes (Dawson and Reynolds 1975), 1-aryl-propenes and propynes (Izawa et al 1973), benzylidene anilines (Inamoto et al 1974), benzonitriles (Bromilo and Brownlee 1975), and $\alpha, \beta$-unsaturated sulphones (Srinivasan $e t$ al 1986). The ${ }^{13} \mathrm{C}$ NMR chemical shifts of carbonyl groups conjugated with aryl rings have generally been observed to be 'insensitive' to substituent effects (Mathias 1966; Dhami and Stothers 1965, 1967) and only limited reports of their linear free energy relationships have appeared. Benzoic acids exhibit carbonyl carbon ${ }^{13} \mathrm{C}$ chemical shifts of range $2.4 \mathrm{ppm}$ (Niwa and Yamazaki 1974). A series of N-phenacylpyridinium bromides (Harch et al 1977) with substituents in the pyridine ring exhibit greater sensitivity for the carbonyl resonance.

The substituent induced chemical shifts (SCS) of $s p^{2}$ and $s p$ carbons directly bonded to the ring have been observed to show 'reverse substituent effects' (Bromilow et al 1977, 1981; Brownlee and Craik 1981; Srinivasan et al 1986), i.e., electron-attracting substituents apparently increase the electron density on the 
carbon concerned whereas electron-releasing substituents decrease it. This phenomenon has been attributed to the polarisation of the $\pi$-system of the side chain. Almost all studies in this area have involved carbon bonded to oxygen, nitrogen or other carbon atoms (Butt and Topsom 1980, 1982; Solcaniova et al 1976, 1980). In this study, ${ }^{13} \mathrm{C}$ NMR chemical shifts of carbonyl carbons of several 4-substituted 1-naphthamides have been measured and the SCS have been analysed by the DSP equation. The results of the analysis have been compared with those of the benzamides.

\section{Experimental}

Substituted 1-naphthoic acids were prepared by the hypobromite oxidation of the corresponding acetonaphthones (Ananthakrishna Nadar and Gnanasekaran 1978). The acids were converted into amides by the acid chloride method. Carbon-13 NMR spectra were run on Nicolet NT-300 spectrophotometer at $75.45 \mathrm{MHz}$ using $5 \mathrm{~mm}$ sample tubes. The solvent is DMSO- $d_{6}$ and $16 \mathrm{~K}$ data points were used for all the samples. The chemical shifts were measured relative to internal TMS standard and are accurate within $0.02 \mathrm{ppm}$.

\section{Results and discussion}

The carbonyl carbon of aromatic amide group resonates near $170 \mathrm{ppm}$. These are well removed from other carbons in the spectrum and these absorptions are all of low intensity due to minimal nuclear overhauser enhancement and to their relatively long relaxation times. So these carbons can be unequivocally assigned. The side chain carbonyl carbon chemical shifts of several 4-substituted 1naphthamides are presented in table 1 along with the relevant data for para-substituted benzamides.

Examination of data in table 1 shows that substituents have a relatively small influence on ${ }^{13} \mathrm{C}$ chemical shifts $(\Delta \delta=1.6 \mathrm{ppm})$. All substituents cause upfield shift of the carbonyl carbon resonance compared to unsubstituted compound. The observed upfield shift for electron-attracting substituents is contrary to the

Table 1. Carbon-13 NMR chemical shifts of carbonyl carbons of naphthamides and benzamides.

\begin{tabular}{|c|c|c|c|c|c|c|c|c|}
\hline \multirow[b]{2}{*}{ Substituent } & \multirow[b]{2}{*}{$\mathrm{OCH}_{3}$} & \multirow[b]{2}{*}{$\mathrm{CH}_{3}$} & \multicolumn{5}{|c|}{ 4-Substituted 1-naphthamides } & \multirow[b]{2}{*}{$\mathrm{NO}_{2}$} \\
\hline & & & $\mathbf{H}$ & $\mathbf{F}$ & $\mathrm{Cl}$ & $\mathrm{Br}$ & I & \\
\hline$\delta(\mathrm{ppm})$ & $170 \cdot 60$ & $170 \cdot 82$ & $170 \cdot 89$ & $169 \cdot 80$ & $169 \cdot 88$ & 169.94 & 170.01 & $169 \cdot 28$ \\
\hline$\Delta \delta(\mathrm{ppm})$ & $-0 \cdot 29$ & -0.07 & 0.00 & $-1 \cdot 09$ & $-1 \cdot 01$ & -0.95 & -0.88 & -1.61 \\
\hline \multicolumn{9}{|c|}{ para-substituted benzamides } \\
\hline Substituent & $\mathrm{OCH}_{3}$ & $\mathrm{CH}_{3}$ & $\mathbf{H}$ & $\mathbf{F}$ & Cl & $\mathrm{Br}$ & $\mathrm{NO}_{2}$ & \\
\hline$\delta(\mathrm{ppm})$ & $167 \cdot 85$ & $168 \cdot 20$ & $168 \cdot 29$ & $167 \cdot 27$ & $167 \cdot 22$ & $167 \cdot 32$ & $166 \cdot 64$ & \\
\hline$\Delta \delta(\mathrm{ppm})$ & -0.44 & -0.09 & 0.00 & -1.02 & $-1 \cdot 07$ & -0.97 & $-1 \cdot 65$ & \\
\hline
\end{tabular}




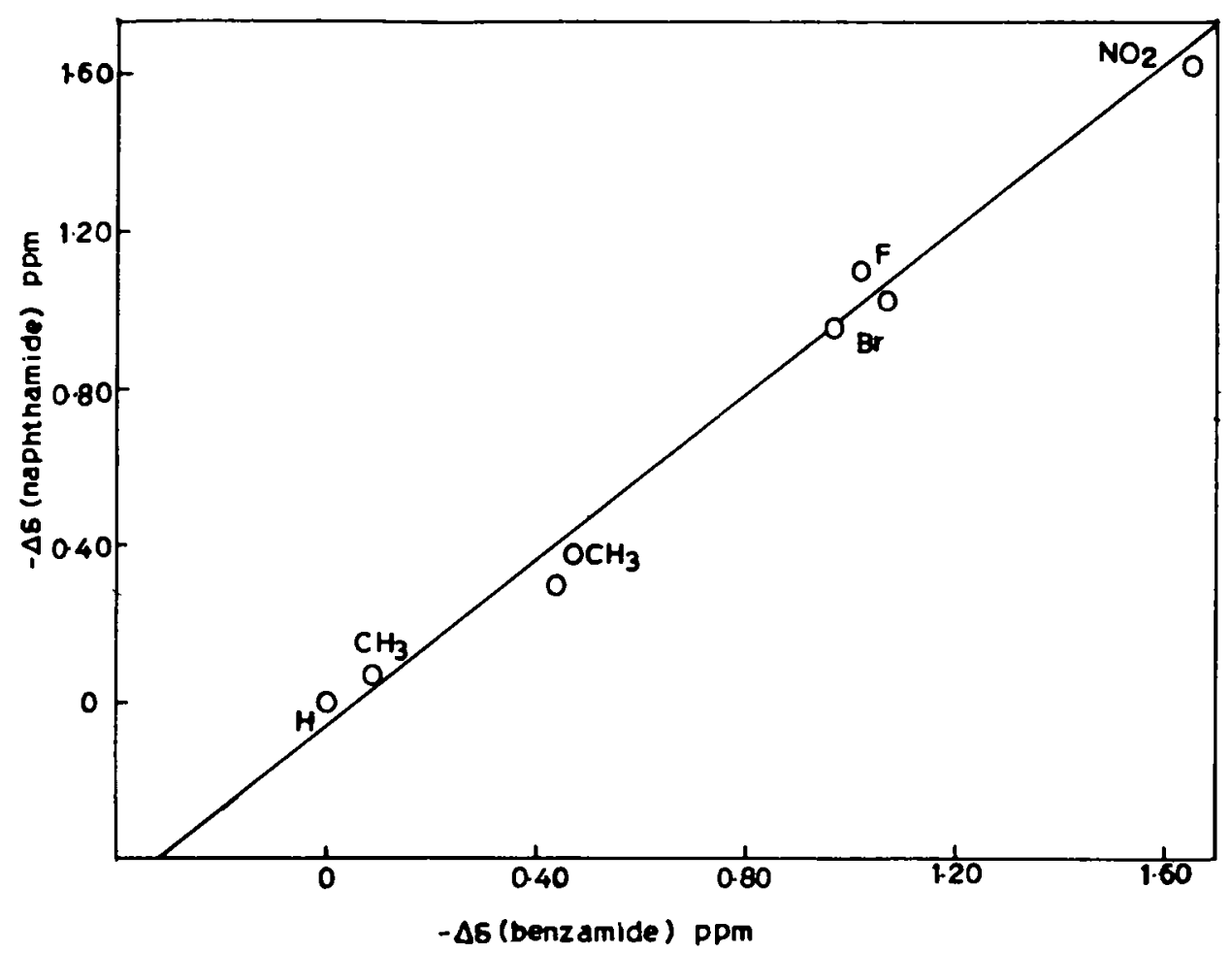

Figure 1. Plot of SCS of 4-substituted 1-naphthamides versus para-substituted benzamides. $\Delta \delta(\mathrm{ppm})$ values for benzamides are from Bromilow et al (1981).

expectation that they should withdraw electron density, decrease the shielding and cause a down-field shift. The plot of SCS of 4-substituted 1-naphthamides versus SCS of para-substituted benzamides is linear (figure 1) with a slope of 1.00 $(r=0.994$; s.d. $=0.07)$. This indicates that the mechanism for transmission of electronic effects of the substituents in these two series is similar.

The SCS were analysed by the single parameter equation and the correlations obtained were poor. Since single parameter equation has failed, the SCS have been analysed by the DSP equation in the form

$$
\mathrm{SCS}=\rho_{I} \sigma_{I}+\rho_{R} \sigma_{R} \text {. }
$$

The DSP methods (Ehrenson 1964) provides the relative magnitudes of various modes of transmission of substituent effects like $\rho_{I}$ and $\rho_{R}$ values, which are not obtainable from single parameter treatment. The DSP analysis gave the following regression equation

$$
\begin{aligned}
\mathrm{SCS}= & -2 \cdot 25 \sigma_{I}-0.51 \sigma_{R}^{(B A)} \\
& \pm 0.15 \quad \pm 0.15 \quad(n=8 ; R=0.990)
\end{aligned}
$$

As seen from the results of the regression analysis, the inductive effect contributes more to the chemical shifts of the carbonyl carbons than the resonance effect. The $\rho_{I}$ term is negative and its magnitude is quite comparable to that of para-substituted 
benzamides $\left(\rho_{I}=-2 \cdot 4\right)$. The negative sign on $\rho_{I}$ term indicates the operation of reverse SCS effect. This is due to the fact that $\pi$-polarisation of the carbon-oxygen bond is the major contribution to the inductive component of ${ }^{13} \mathrm{C}$ SCS values (Bromilow et al 1981). This type of polarisation is the 'localised polarisation' involving the separate polarisation of the side-chain as shown in chart 1 .



Chart 1.

In chart 1 , if $\mathrm{X}$ is an inductive electron-attracting substituent, a dipole on $\mathrm{X}$ or near $\mathrm{C}-\mathrm{X}$ is set up, the interaction of this dipole through space of the molecular cavity results in the polarisation shown. The net result is that the inductive electronattracting substituent increases the electron density at the carbonyl carbon and hence increases the shielding to cause upfield shift.

Bromilow et al (1981) have shown that for series of the general form $\mathrm{X}-\mathrm{C}_{6} \mathrm{H}_{4}-\mathrm{COZ}$, the inductive effect of $\mathrm{X}$ on SCS of the side chain carbonyl carbon is largely determined by localised $\pi$-polarisation of $\mathrm{C}=\mathrm{O} \pi$-electrons and is independent of the adjacent $Z$ group. On the other hand, the resonance effect of $X$ on SCS varies from one series to another, and is determined by both the inductive and resonance effects of the $Z$ group. When $Z$ is a strong resonance donor $\left(\mathrm{Z}=\mathrm{NH}_{2}\right), \rho_{R}$ is negative, and when $\mathrm{Z}$ is neutral $(\mathrm{Z}=\mathrm{H})$ or inductive donor $\left(\mathrm{Z}=\mathrm{CH}_{3}\right), \rho_{R}$ is positive. The observed negative $\rho_{R}$ value for the present system is in accordance with the observations reported by Bromilow et al (1981).

The carbonyl carbon resonance of 2-naphthamide (168.15 ppm) is very close to that of benzamide (168.29 ppm). Compared to benzamide and 2-naphthamide the carbonyl carbon resonance of 1-naphthamide $(170.89 \mathrm{ppm})$ occurs at down field. This may be due to the peri-hydrogen interaction in 1-naphthamide. The peri-hydrogen forces the amide group out of the naphthalene ring and thereby reduces the conjugation with the aromatic ring. This decrease in conjugation increases the deshielding of the carbonyl carbon and hence downfield resonance occurs.

It is reasonable to assume that the conjugative interaction between the carbonyl group and the aromatic ring will be maximum, if the dihedral angle, $\theta$, between the aromatic ring and the carbonyl group is zero. This interaction is minimum if $\theta=90^{\circ}$ (chart 2). 


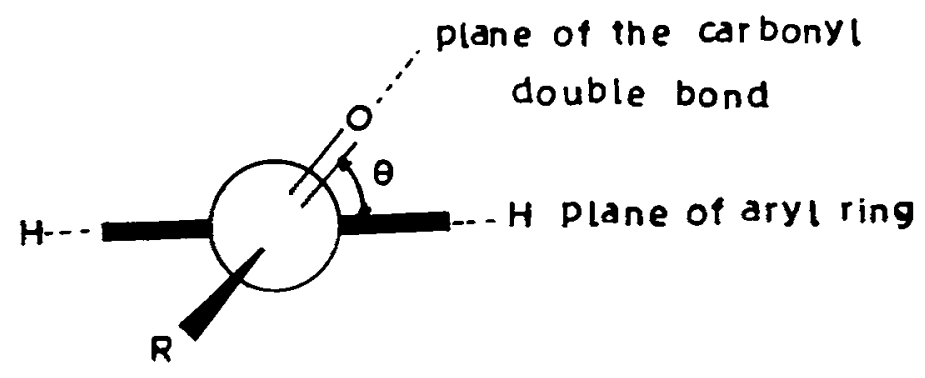

Chart 2.

Table 2. Dihedral angle in 4-substituted 1-naphthamides.

\begin{tabular}{lccccccc}
\hline Substituent & $\mathrm{OCH}_{3}$ & $\mathrm{CH}_{3}$ & $\mathrm{H}$ & $\mathrm{F}$ & $\mathrm{Cl}$ & $\mathrm{Br}$ & $\mathrm{NO}_{2}$ \\
\hline$\theta^{\circ}$ & 21.8 & 21.2 & 21.1 & 20.8 & 21.4 & 21.2 & 21.3 \\
\hline
\end{tabular}

The chemical shifts of carbonyl carbon in benzene derivatives can be taken as that typical for a planar system where $\theta$ is zero. A relationship between the interplanar angle $\theta$ and the carbonyl carbon chemical shift has been proposed based on model compounds with complete $\left(\theta=0^{\circ}\right)$ and minimum $\left(\theta=90^{\circ}\right)$ orbital overlap (Dhami and Stothers 1964). The observed carbonyl carbon resonance $\delta_{o}^{x}$, the interplanar angle $\theta$ and the chemical shift $\delta_{b}^{x}$ for benzene analogues are related by the following expression:

$$
\cos ^{2} \theta=\left[\left(\delta_{b}^{x}+20\right)-\delta_{o}^{x}\right] / 20 .
$$

Substituting the $\delta_{b}^{x}$ (Bromilow et al 1981) and $\delta_{o}^{x}$ values (present data) in (3), $\theta$ values are evaluated for 1-naphthamide and several 4-substituted 1-naphthamides (table 2). In all the naphthamides, the amide group is out of the plane of the naphthalene ring to an extent of $21^{\circ}$.

\section{Acknowledgements}

The authors thank the Managing Board of the VHNSN College, Virudhunagar for encouragement and also thank the DST, New Delhi, for a research grant (to CG). Thanks are also due to Prof. P Ananthakrishnan for his encouragement.

\section{References}

Ananthakrishna Nadar P and Gnanasekaran C 1978 J. Chem. Soc. Perkin 2672

Bromilow J and Brownlee R T C 1975 Tetrahedron Lett. 3617

Bromilow J, Brownlec R T C and Craik D J 1977 Aust. J. Chem. 30351

Bromilow J, Brownlee R T C, Craik D J, Fiske P R, Rowe J E and Sadek M 1981 J. Chem. Soc. Perkin 2 753 
Brownlee R T C and Craik D J $1981 \mathrm{~J}$. Chem. Soc. Perkin 2760

Butt G and Topsom R D 1980 Spectrochim. Acta A36 811

Butt G and Topsom R D 1982 Spectrochim Acta A38 301

Dawson D A and Reynolds W F 1975 Can. J. Chem. 53373

Dhami K S and Stothers J B 1964 Tetrahedron Lett. 631

Dhami K S and Stothers J B 1965 Can. J. Chem. 43 479, 510

Dhami K S and Stothers J B 1967 Can. J. Chem. 45233

Ehrenson S 1964 Prog. Phys. Org. Chem. 2195

Hamer G K, Peat I R and Reynolds W F 1973 Can. J. Chem. 51897

Harch A D, Johnson S and Boykin D W 1977 Chem. Commun. 119

Inamoto N, Kushida K, Masuda S, Ohta H, Saton S, Tamura Y, Takumaru K, Tosi K and Yoshida M 1974 Tetrahedron Lett. 3617

Izawa K, Okuyama T and Fueno T 1973 Bull. Chem. Soc. Jpn. 462881

Mathias A 1966 Tetrahedron 22217

Niwa J and Yamazaki M 1974 Chem. Lett. 765

Solcaniova E, Toma S and Gronowilz S 1976 Org. Magn. Reson. 8439

Solcaniova E, Toma S and Fiedlerova A 1980 Org. Magn. Reson. 14181

Srinivasan C, Ganesan P K, Shunmugasundaram A and Arumugam N 1986 Proc. Indian Acad. Sci.

(Chem. Sci.) 9733 